\title{
D. Julio Saavedra Molina (1880-1949)
}

\begin{abstract}
Continuando las investigaciones iniciadas por su maestro Federico Hanssen, el profesor chileno Julio Saavedra Molina dedicó los últimos años de su vida principalmente al estudio de la métrica, aunque no abandonó su vivo interés por los problemas pedagógicos, sociales y culturales de su patria. ${ }^{1}$ Fue durante este período cuando empezó nuestra amistad epistolar y cuando me escribió las cartas que a continuación se imprimen, en las que explica la génesis de algunas de sus teorías y el método que empleaba en sus estudios. Había preparado una Teoria de la versificación "basada en un estudio del octosílabo y del arte mayor, y también en parte del eneasílabo, el endecasílabo y el tredecasílabo", pero se vio obligado a "descuartizarla" y publicarla en secciones, ${ }^{2}$ destruyendo así la unidad de una de las obras más extensas y originales que se han escrito sobre la versificación castellana. "Mi principal punto de vista", dice en la carta del 9 julio I94 $\mathrm{I}$, "es que las nociones básicas de la métrica son dé naturaleza subjetiva, personales; y ésta es la causa de que cada autor aprecie los mismos hechos físicos de modo diferente. Y como, no dándose cuenta de eso, los autores tratan la materia como si fuese de naturaleza
\end{abstract}

1 Son numerosos sus estudios sobre la educación, la pronunciación castellana, la enseñanza del francés, temas literarios (especialmente de Rubén Darío), y filosofía social mencionados por Raúl Silva Castro en "Semblanza..." (Introducción a Teoría del poema).

2 El octosilabo castellano (Santiago: Universidad de Chile, 1945): Tres grandes metros: el eneasilabo, el tredecasílabo y el endecasilabo (Santiago: Universidad de Chile, 1946); El verso de arte mavor (Santiago: Universidad de Chile, 1946). Otros estudios importantes, no incluidos en este grupo son: El verso que no cultivó Rubén Dario (Santiago: Prensa de la Universidad de Chile, 1933); Los bexámetros castellanos y en particular los de Rubén Dario (Santiago: Prensa de la Universidad de Chile, 1935); "El fallo de Benot en el pleito Barra-Vila", El Mercurio, Santiago, 7 de mayo de 1939, p. 2; "¿Qué es poesía?" Atenea, Universidad de Concepción, Chile, LXXVII, No. 232, 1944, págs. 56-89; La versificación neo. clásica y la obra poética del Dr. Juan Francisco Ibarra y Dos comentarios sobre versificación neoclásica por el Dr. Juan Francisco Ibarra (Santiago; Universidad de Chile, 1946). Cf. también carta, 14 Sept. 1945. 
objetiva, idénticamente observable por cada cual, unos acusan a los otros de no entender ni saber nada". Dejó en manuscrito la última y más importante parte de su obra, la teoría, y un estudio detallado de la cuaderna vía. El Instituto de Filología, cumpliendo "un sencillo, pero sentido acto de gratitud para con uno de los más laboriosos investigadores en el campo de la versificación con que ha contado nuestro país", publicó en el tomo VI (I950-I95I) del Boletín de Filología las dos obras, tantas veces mencionadas en estas cartas: Teoría del poema. Dos ensayos distintos: poesia y verso, y un solo tema en verdad: el poema $y$ El verso de clerecia, sus irregularidades y las doctrinas métricas de D. Federico Hanssen. En el largo prefacio titulado "Semblanza de don Julio Saavedra Molina", su amigo Raúl Silva Castro nos da algunos detalles de la personalidad y del carácter del simpático e ilustre profesor, y observa en conclusión, expresando los sentimientos de todos los que le conocieron: "Y esas dos dimensiones del espíritu, la amistad y el saber, convivieron en él en grado tan eminente que en esta hora lo lloran a la par el amigo y el admirador, ambos con pesar idéntico, ambos con agradecida solicitud". Otros aspectos de su carácter se revelan en estas cartas - sobre todo el buen humor y la humildad del verdadero sabio. Las cartas tienen también un valor especial para los críticos literarios: son una parte integrante, aunque suplementaria, de la Teoría del poema. Pero son mucho más: son una revelación de la psicología de un escritor durante el período de creación y desarrollo de una obra de teoría literaria; son un retrato íntimo en miniatura de uno de los hispanistas más importantes del siglo veinte; son un modelo de literatura epistolar.

D. C. Clarke,

3 Publicaciones del Instituto de Investigaciones Histórico-Culturales de la Facultad de Filosofía y Educación de la Universidad de Chile, Santiago, 1952. 358 págs, 